\title{
AGRICULTURE DROUGHT RISK MANAGEMENT USING STANDARDIZED PRECIPITATION INDEX AND AEZ MODEL
}

\author{
Nazarifar M.H., Momeni R., Kanani M.H., Research Assistants \\ College of Abouraihan, University of Tehran, Tehran, Iran \\ E-mail: nazarifar@ut.ac.ir, rmomeni@ut.ac.ir, mhkanani@ut.ac.ir
}

\begin{abstract}
The objective of this study was to assess the drought risk management in the region under study. The SPI method was adopted for drought monitoring in Hamadan Province, Iran. The temporal and spatial extent of the area vulnerable to drought was delineated using AEZ model, GIS and other softwares. Five zones were recognized based on the drought severity index. Selection of compatible crops with respect to climate and land production capability of a region specially in drought condition is one of the effective elements to increase the water productivity in agriculture, based on Agro-ecological Zoning (AEZ) model, developed by FAO, suitable spatial extension of wheat cultivation, which is the main crop in Hamadan Province, were delineated. According to this study the most suitable lands potentially available for wheat production are located in the north-east region and a part of the central region, where as, least suitable ones can be observed in the north-east and the south - east regions. The results of the risk analysis study show that south-east, north and central regions are susceptible to longest duration intense droughts where as long duration droughts are intensive in north, west and south-east regions. The overlaid and integrated maps of risks with the maps obtained after applying the AEZ model resulted into the map of spatial suitability of potential crop production for each class of risk (longest duration and most intensive durations). This enables the decision makers to define spatial priority of crop cultivation and manage various potential regions susceptible to drought risks.
\end{abstract}

\section{KEY WORDS}

Hamadan; Drought; GIS; Agro-ecological zoning.

Rainfall scarcity, high potential evapotranspiration and water resources constraints are problems in agriculture in Iran. During drought periods, when temperature rises and rainfall reduces, crisis arises at a faster rate. Subsequent loses due to droughts in agriculture sector, as well as direct and indirect vulnerability of agriculture, necessitate the accurate planning on the basis of potential and limited resources for sustainable agriculture. Till 1995 in all countries, there were not major plans for drought mitigation. Therefore, the traditional practice was to organize a task committee casually after the drought occurrence, to reduce the drought damages. These decisions were made, in those offices fast and random immediately after the drought reached to maximum. Therefore, little attention was paid to drought mitigation. The occurrence of several intense and vast droughts in the United States like those of 1996 drew the attention of scientists, planners and the U.S. government in droughts management towards changing the disaster management approach to drought risk management. In drought risk management, the decisions are clear, applicable and dynamic. Moreover, in this approach the emphasis is on alertness and readiness for drought risk mitigations.

As frequency and intensity of drought increases, attention shifts towards reducing drought risk management in most countries. Today, drought risk management in many countries like, the U.S., Canada, Mexico, Australia and European countries is put into effect practiced instead of disaster management (Cline, 2007). It can be concluded from various researches that, obviously, the economical losses and social damages can be reduced through using drought risk management. Thus, researches are conducted to predict the context and update the results. In planning for drought mitigation there has been a shift from disaster management to drought risk management, which is quite difficult when the behavior and characteristic of droughts and expected losses are not predictable. To solve this problem, it is necessary to locate and monitor the areas of high drought risk and potentially 
susceptible to drought through adopting take up the necessary precautions and plans in order to reduce drought risk. The indices used for drought monitoring are: precipitation percentile, percent of normal precipitation, Palmer Drought Severity Index (PDSI) and Standardized Precipitation Index (SPI), etc. There is an extensive literature for qualitative assessment of droughts including indices, models, and water balance simulation (Alley,1984; Byun and Wilhite,1999; Flug and Campbell,2005; Karl and Knight, 1985; Karamouz, Torabi and Araghinejad,2004; McKee, Doesken and Kleist, 1993; Palmer,1965; Sen,1989; Shin and Salas,2000). In 1965, Palmer developed an index to measure the departure of the moisture supply (Palmer, 1965). Palmer based his index on the supply-and-demand concept of the water balance equation, taking into account more than just the precipitation deficit at specific locations. The objective of the Palmer Drought Severity Index (PDSI), as this index is now called, was to provide measurements of moisture conditions that were standardized so that comparisons using the index could be made between locations and between months

(Palmer, 1965). The understanding that a deficit of precipitation has different impacts on groundwater, reservoir storage, soil moisture, snowpack, and stream flow led McKee, Doesken, and Kleist to develop the Standardized Precipitation Index (SPI) in 1993 (McKee, Doesken and Kleist, 1993). The SPI was designed to quantify the precipitation deficit for multiple time scales. These time scales reflect the impact of drought on the availability of the different water resources. Soil moisture conditions respond to precipitation anomalies on a relatively short scale. Groundwater, streamflow, and reservoir storage reflect the longer-term precipitation anomalies. For these reasons, McKee et al. (1993) originally calculated the SPI for 3-, 6-,12-, 24-, and 48-month time scalesMcKee, Doesken and Kleist, 1993). Agroecological Zones (AEZ) method was developed by the Food and Agriculture Organization of the United Nations (FAO) and the International Institute for Applied Systems Analysis (IIASA) $(F A O, 1996)$. As a mechanism method, it was frequently adopted to calculate potential productivity of crops at regional level (Deng, Huang and Rozelle,2006; Fischer and Sun,2001).The second approach, AEZ analysis, combines crop simulation models with land management decision analysis, and captures the changes in agro-climatic resources (Darwin, Tsigas, Lewabdrowski and Raneses,1995; Fischer, Shah, Tubiello and Velthuizen,2005). AEZ analysis categorizes existing lands by agro-ecological zones, which differ in the length of growing period and climatic zone. The length of growing period is defined based on temperature, precipitation, soil characteristics, and topography. The changes of the distribution of the crop zones along with climate change are tracked in AEZ models. Crop modeling and environmental matching procedures are used to identify cropspecific environmental limitations under various levels of inputs and management conditions, and provide estimates of the maximum agronomically attainable crops yields for a given land resources unit. However, as the predicted potential attainable yields from AEZ models are often much larger than current actual yields, the models may overestimate the effects of autonomous adaptation. Cline observed that AEZ studies tend to attribute excessive benefits to the warming of cold high-latitude regions, thereby overstating global gains from climate changes. This model has been used in several fields related to sustainable agriculture (Deng, Huang and Rozelle,2006; Lugue, 2009; Pratap, Pradhan, Lotta, and Nakarmi, 1992; Ravelo and Abril, 2009. Segal, Mandal and Vadivelu,1992; Subramanian, 1983; Venkateshwaralu, Ramakrishna and Rao,1996).

This model offers much scope for developing strategies for efficient natural resource management and in this context, recent advances in remote sensing and GIS have made the task of integration and mapping of a wide range of databases much easier.In this study standard precipitation index(SPI) was adopted for monitoring droughts in Hamadan Province. The intensity and duration of droughts in this region were studied and the areas potentially subject to drought risk were identified. On the basis of probability of occurrence these regions were qualitatively classified and the risk layers were identified. These layers were overlayed on the layers obtained by applying AEZ model and finally the areal extension of wheat cultivation in drought conditions were worked out. 


\section{MATERIAL AND METHODS}

The Study Area. Hamedan province lies between longitudes $48^{\circ} 28^{\prime} 30^{\prime \prime}$ and $49^{\circ} 1^{\prime} \mathrm{E}$ and latitudes $34^{\circ} 36^{\prime}$ and $35^{\circ} 9^{\prime} \mathrm{N}$ and is shown in Figure 1 . The area occupies about 944 $\mathrm{km}^{2}$, with a mean altitude of 1950 m.a.s.l. The climate of the study area is considered to be semi-arid, the annual average precipitation being approximately $300 \mathrm{~mm}$, of which about $37 \%$ occurs during winter. Another feature characterizing the precipitation in the study site is its irregular yearly distribution. The mean air monthly temperature is highest during August $\left(23.45^{\circ} \mathrm{C}\right)$ and lowest during January $\left(-1.91^{\circ} \mathrm{C}\right)$ with an annual average of $10.88^{\circ} \mathrm{C}$.

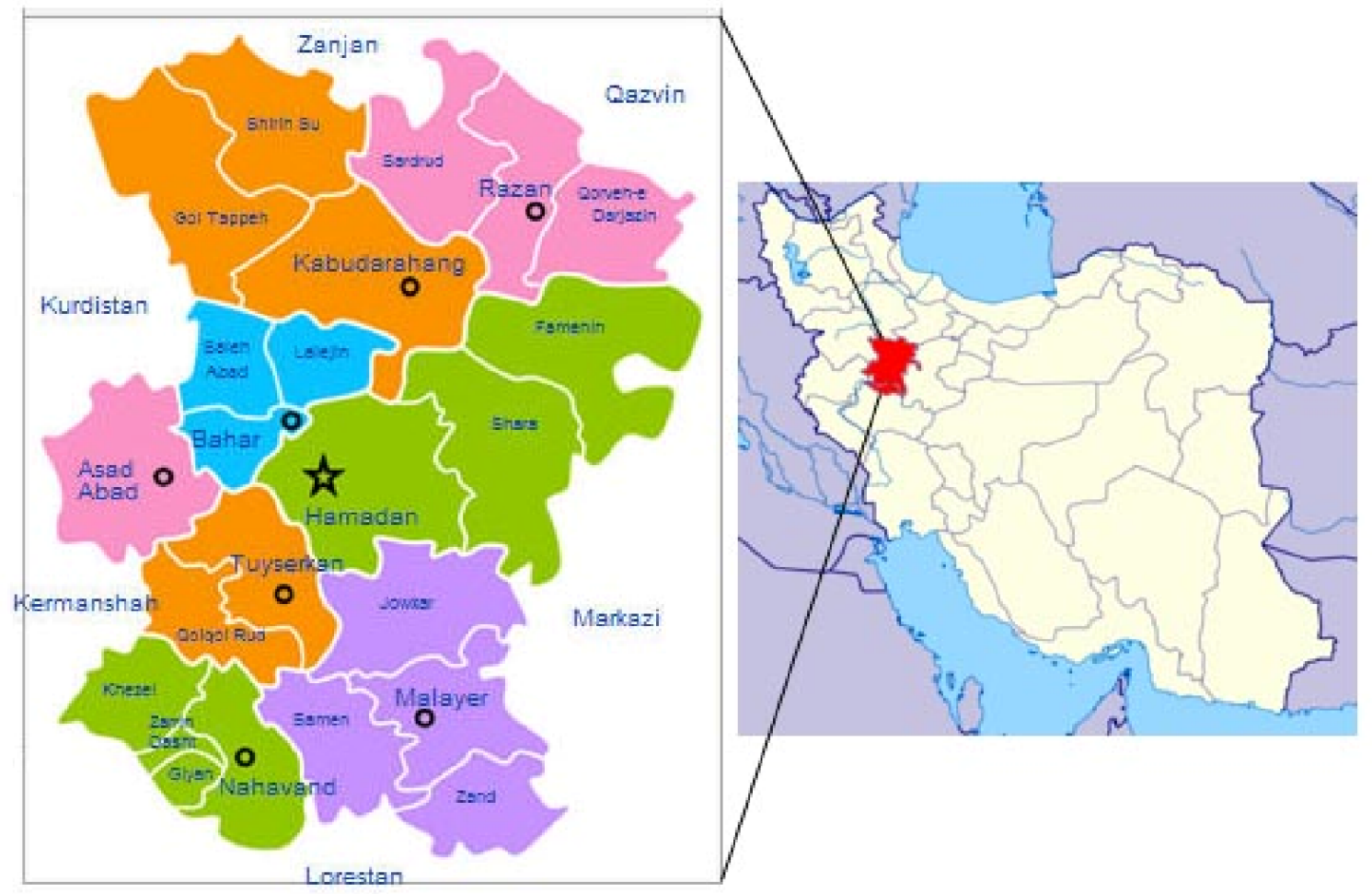

Figure 1 - Location of study area

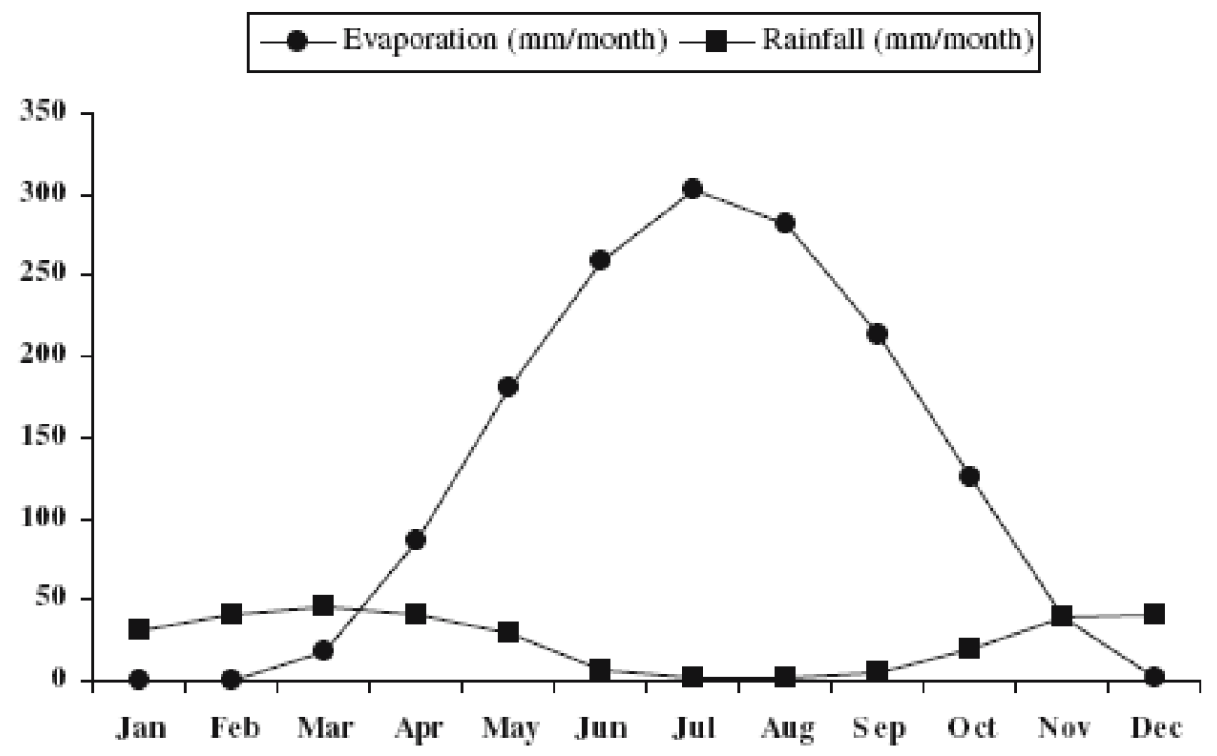

Figure 2 - Monthly rainfall and evaporation in the study area 
The annual potential evaporation far exceeds the annual rainfall (Figure 2) with a mean annual amount of approximately $1505 \mathrm{~mm}$ (1975-2010). The area has complicated land use characteristics, mainly consisting of agricultural and urban/residential areas. Groundwater has been used for various purposes, such as drinking, agricultural, domestic and industrial needs. The most important economic activity of the area is agriculture, the chief crops are garlic (Allium sativum), potato (Solanum tuberosum L.) and wheat (Triticum aestivum L.), with actual irrigation being lower than total theoretical demand, as there is a considerable deficit in relation to the amount of irrigated land.

Data Processing. For this research 29 years (1973-2002) precipitation data of 13 meteorological stations were studied. The data of adjacent stations were also taken into consideration to reduce errors in data interpolations. The run test was used to confirm the homogeneity of the data. Next, the missing data were added or supplemented and erroneous data were corrected by using 29 years common data-period.

SPSS Software was applied to carry out the analysis. Regression analysis was done between the stations and the missing data were estimated using data of different stations with higher correlation coefficient and SPI values. Later, the computed SPI values were utilized for further studies to analyze the beginning and terminating intensity, covering area, frequency or return period, duration and the probability of occurrence of drought.

The following equation was used to calculate the probability of occurrences and the corresponding risk values:

$$
\mathrm{P}(\mathrm{N}, \mathrm{m}, \mathrm{n})=(\mathrm{n}-\mathrm{m}+1) /(\mathrm{N}+\mathrm{n}-2 \mathrm{~m}+2) \ldots \ldots \ldots(1)
$$

where $\mathrm{N}$ is the length of data, $\mathrm{m}$ is the duration of drought and $\mathrm{m}$ is the return period. After quantifying the related risk of return periods of various drought events and with respect to the severity and the longest duration, the corresponding probability of occurence to the amount of risk was calculated. The available software in GIS environment such as Arclnfo and ArcView were used to prepare the drought maps of the region under study. The ArcView software was applied to draw the maps and iso-intensity curves of droughts. Furthermore, Arclnfo Software was used to convert the geographical coordinates to UTM coordinate system.

In this study, the 3IDW interpolation method was applied for delineating spatial extension of droughts. To estimate the values of parameters of IDW interpolation technique, trial and error procedure was adopted and the drought maps for various durations $(1,3,6,12$ and 24 months), as well as, the maps for the longest durations, the maps of amount of risk involved in the occurrence, and the longest and most sever droughts were prepared.

In addition, to prepare AEZ maps, the physiological characteristics, also the phonological parameters of wheat crop were studied. Furthermore, the optimum and the extreme conditions of this crop were carefully investigated. Later, SPSS was used to perform statistical analysis to prepare all the digital layers for climatologically factors. In order to apply AEZ model, the required maps were scanned. These maps were digitized using R2V software to develop a data base containing land information of the region. Later, these maps were edited, and necessary corrections were made through Arclnfo software to convert the coordinate system into UTM. The descriptive information of maps were added using ArcView software. Finally, the maps were classified based on the required conditions for the crop the topographical maps contour lines distanced with 100 meters were drawn to prepare the elevation map. By mapping Triangulate Irregular Network (TIN) on topographical network, the digital elevation model (DEM) was developed. By converting data for each $500 \times 500$ pixel in ArcView software and other extensions (viz. 3D analysis), the slope values were computed.

The land type and the soil depth information layers were digitized using maps of land quantities of the scale 1:250,000 which were procured from "soil Research Office". Moreover, descriptive information was assigned to the maps. 
The capabilities of ArcView software such as rational function AND and the spatial query and map calculator were utilized to compose and overlay the maps as well as to delineate and introduce the suitable places for wheat crop.

In order to compare the maps more accurately, they were normalized between 0 and 1 . These were classified into five categories (i.e. highly suitable, suitable, average, weak and unsuitable) from crop-yield aspect. Finally, using AEZ the developed maps were overlaid. The risk maps were also overlaid for further analysis, obtaining the results and drawing conclusions.

\section{RESULTS AND DISCUSSIONS}

A sample of result of the risk analysis for the longest duration, most intense or sever droughts for 20 years return period, and the corresponding probability of occurrence for various risk values were calculated and presented in Table 1. Risk maps of the longest durations and most sever droughts for 20 years return periods are given in Figures (3) and (4). As it is observed, the amount of risk for the longest drought duration is more in north, west and south-east regions.

Table 1 - Risk values and probability of occurrence for 20 years return period drought

\begin{tabular}{|c|c|c|c|c|c|c|}
\hline \multirow[b]{2}{*}{ Station } & \multicolumn{3}{|c|}{ Longest Duration (month) } & \multicolumn{3}{|c|}{ Intensity according to SPI } \\
\hline & $\begin{array}{l}\text { Ddrought } \\
\text { duration month }\end{array}$ & $\begin{array}{c}\text { Risk } \\
\text { percent }\end{array}$ & $\begin{array}{l}\text { Probability of } \\
\text { occurrence }\end{array}$ & $\begin{array}{l}\text { Duration } \\
\text { (month) }\end{array}$ & $\begin{array}{c}\text { Risk } \\
\text { percent }\end{array}$ & $\begin{array}{c}\text { Probability of } \\
\text { occurrence }\end{array}$ \\
\hline Aagtappa & 34 & 76.47 & probable & 26 & 51.00 & probable \\
\hline Bahar & 49 & 59.57 & average & 43 & 62.86 & high \\
\hline Gonbad & 28 & 40.00 & possible & 28 & 54.00 & probable \\
\hline Jowkar & 87 & 53.66 & probable & 87 & 53.66 & probable \\
\hline Keytoo & 66 & 55.56 & probable & 66 & 55.56 & probable \\
\hline Korijan & 43 & 62.86 & high & 43 & 62.86 & high \\
\hline Nashr & 31 & 90.91 & expected soon & 31 & 90.91 & Expected soon \\
\hline Shoorin & 47 & 60.47 & high & 31 & 80.91 & high \\
\hline Dargazin & 42 & 63.64 & high & 42 & 63.64 & high \\
\hline Hamadan & 36 & 71.43 & high & 25 & 64.00 & high \\
\hline Malayer & 32 & 84.62 & high & 32 & 84.62 & high \\
\hline Novejeh & 62 & 56.16 & probable & 62 & 56.16 & probable \\
\hline Soolan & 39 & 66.67 & high & 39 & 66.67 & high \\
\hline Ghazvin & 35 & 71.68 & high & 35 & 73.68 & high \\
\hline Kermanshah & 53 & 58.18 & probable & 53 & 58.18 & probable \\
\hline Saghez & 34 & 76.47 & high & 34 & 76.47 & high \\
\hline Sanandaj & 37 & 69.57 & probable & 37 & 69.57 & high \\
\hline
\end{tabular}

The results obtained from the application of AEZ model were used to draw the zoning maps. These maps show spatial variation of the capable regions for crop cultivation in five classes. Figure (5) presents the spatial variation of capability of lands for wheat cultivation in Hamadan Province. According to this study the most suitable lands potentially available for wheat production are located in the north-east region and a part of the central region, where as, least suitable ones can be observed in the north-east and the south - east regions.

The utilities of ArcView software makes it possible to overlay and integrate the maps of drought risk obtained from AEZ model. Thus, the maps of spatial variations of suitability of crop production for each class of risk of occurrence (longest duration and most intensive) of droughts were obtained. These are presented in Figures (6) and (7).Based on the results obtained it is clear that the priority of cultivation of a crop in a class of drought will be in regions having higher spatial suitability of crop production potential. In other words, in a region located in a drought class the spatial suitability of crop production is variable. Therefore, it is necessary to allocate higher priority to regions with higher crop production potential in agricultural drought risk management. 


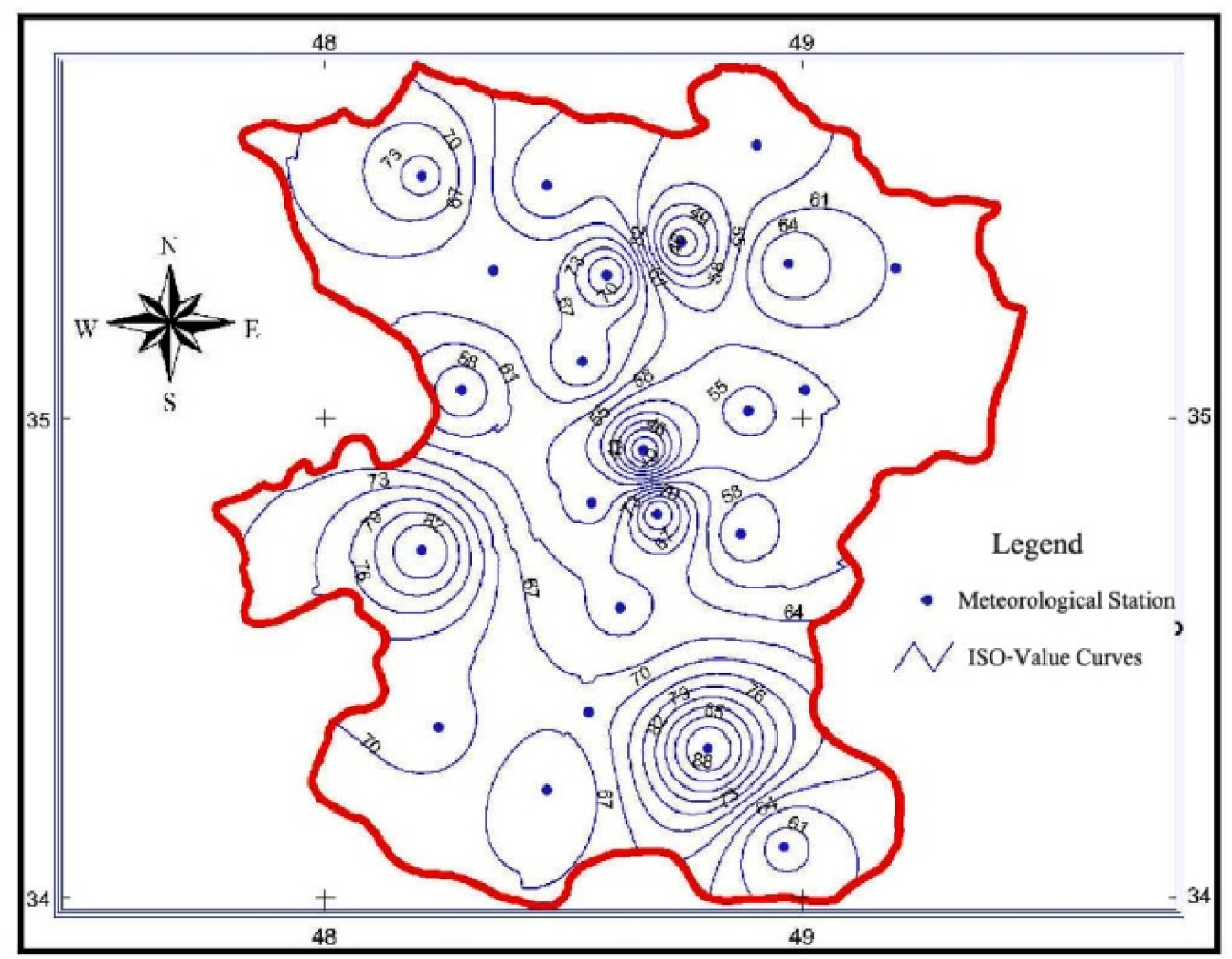

Figure 3 - Map of probability of occurrence of most intensive durations potential

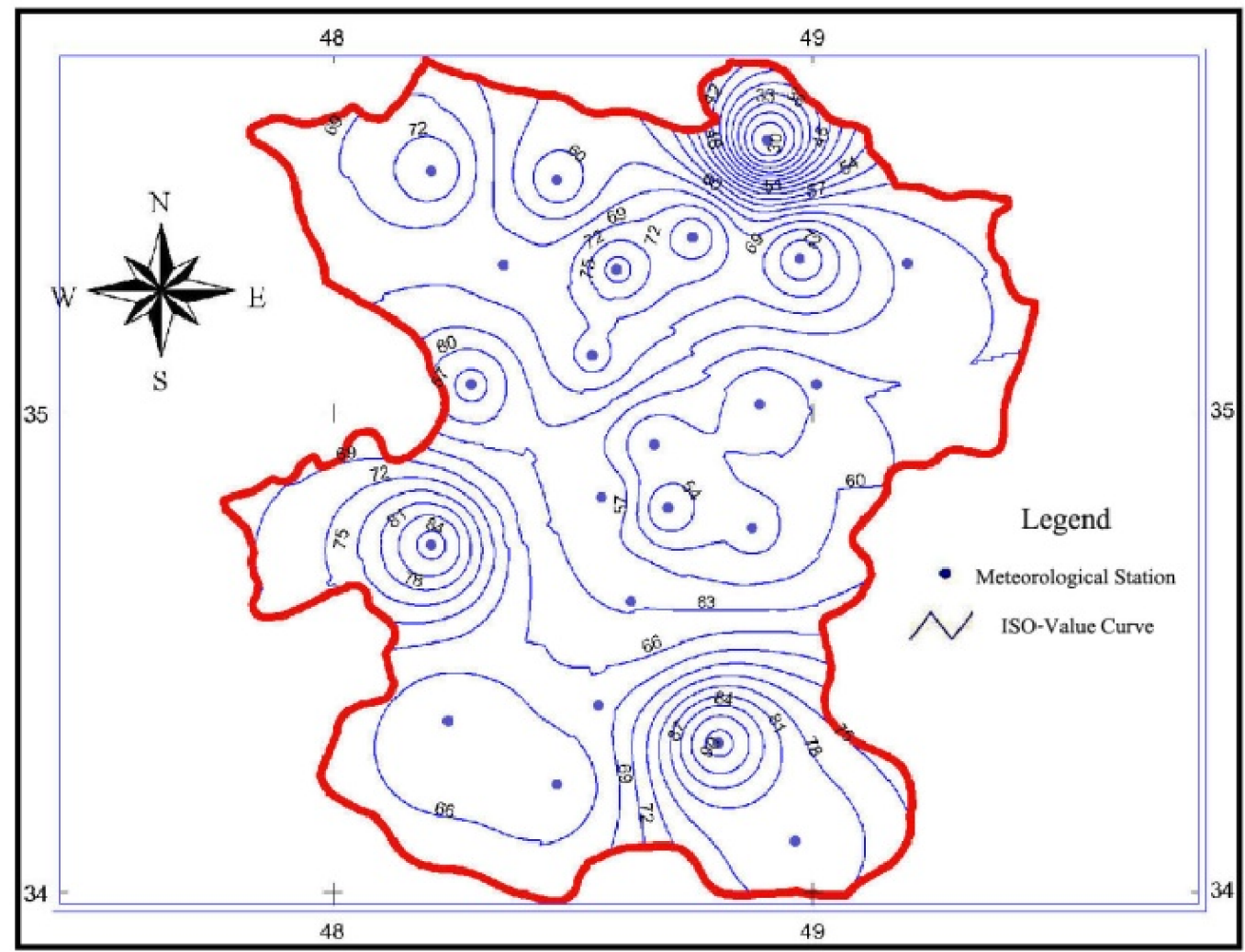

Figure 4 - Map of probability of occurrence of longest durations 


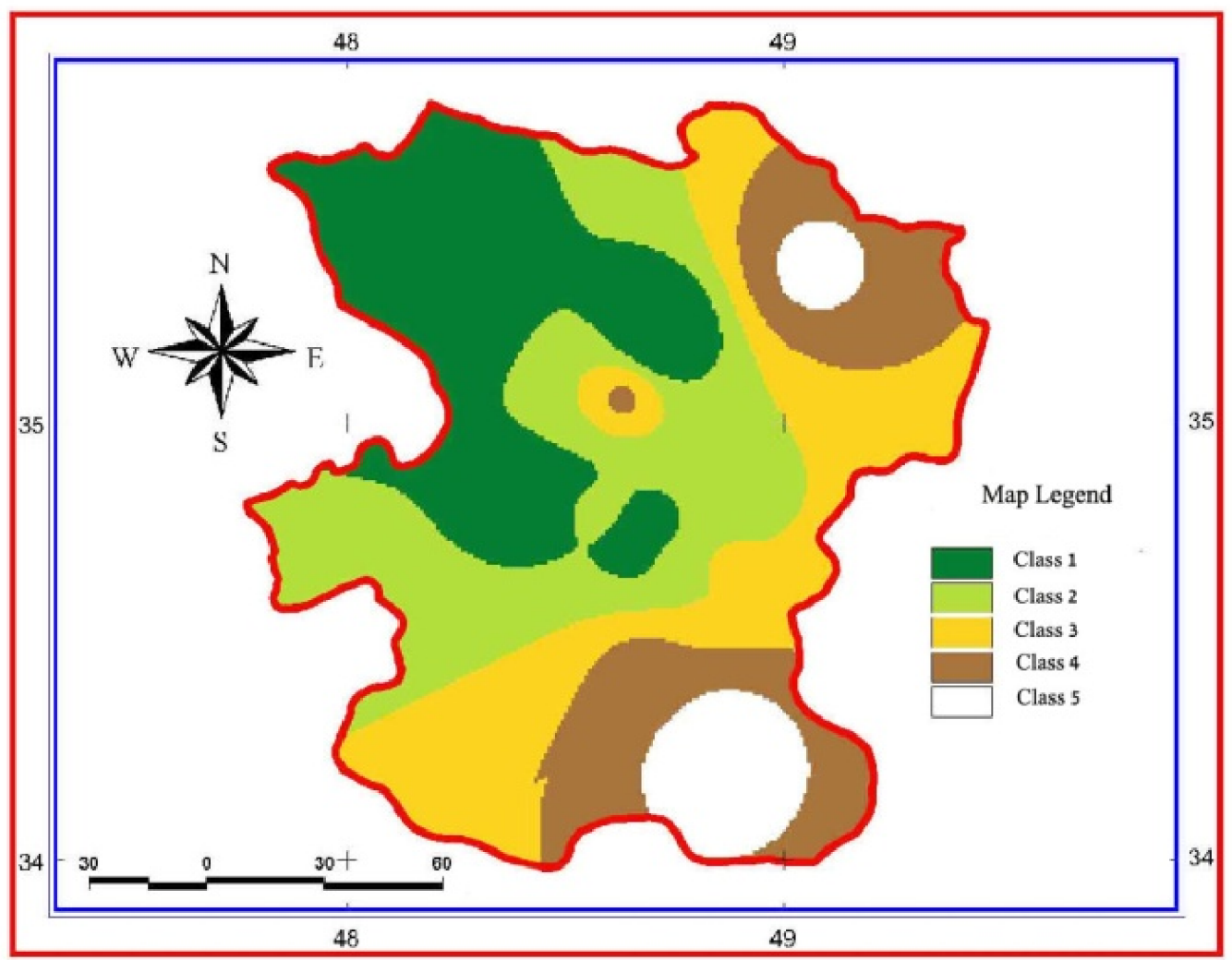

Figure 5 - Spatial variation of Classified land capabilities for wheat production

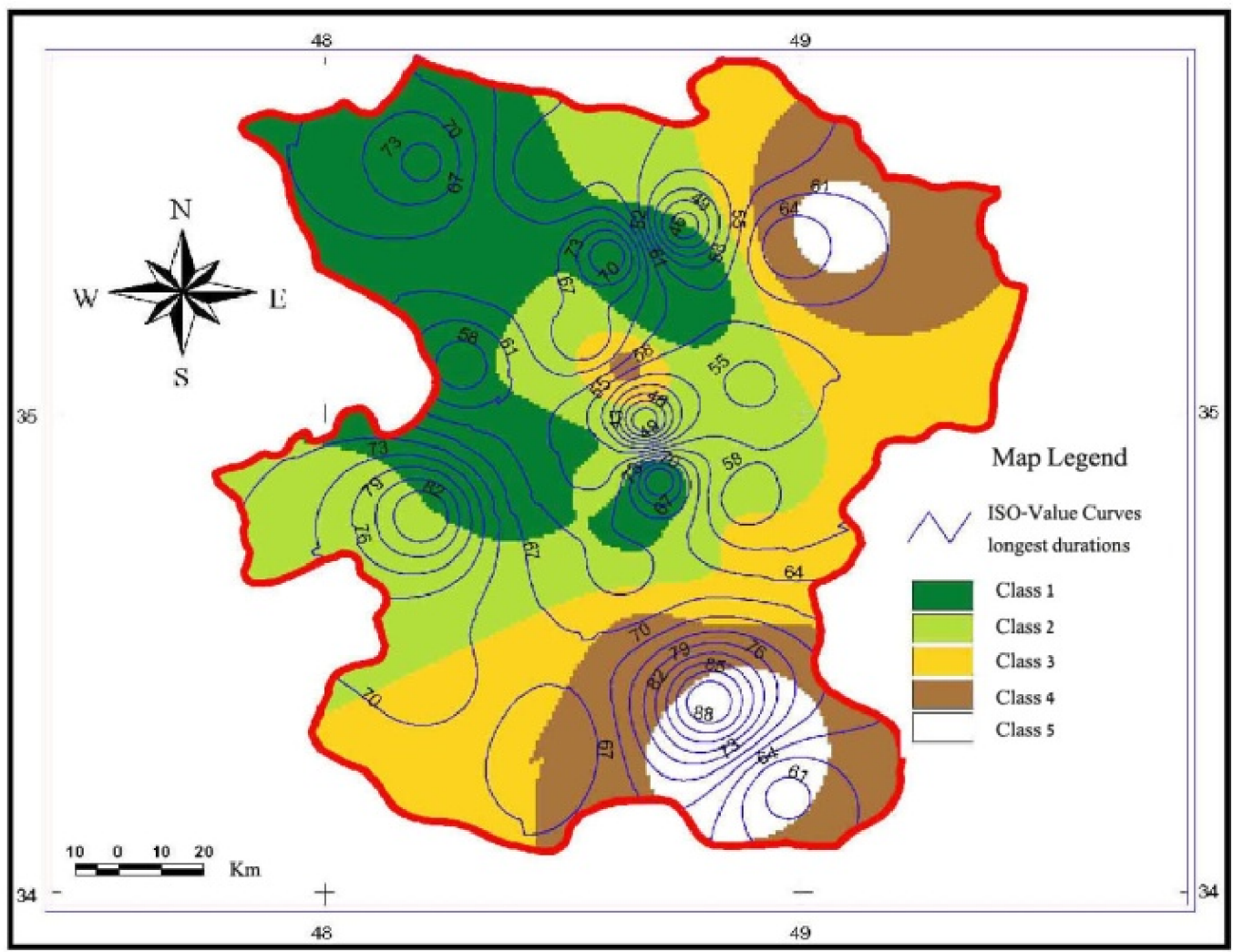

Figure 6 - Overlaid and integrated map of probability of occurrence of longest durations with map of spatial variation of production potential 


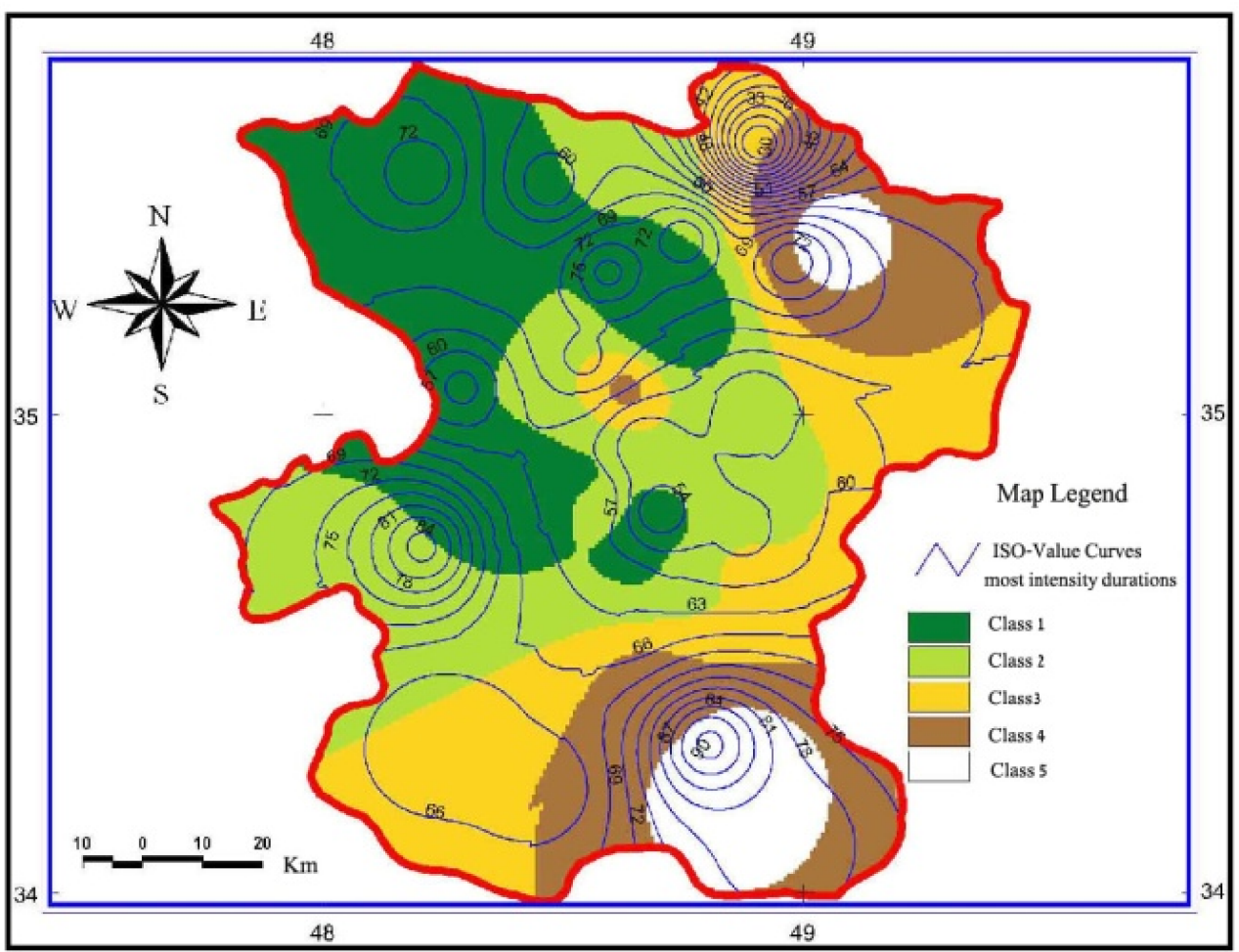

Figure 7 - Overlaid and integrated maps of probability of occurrence of most intensive durations with map of spatial variation of production potential

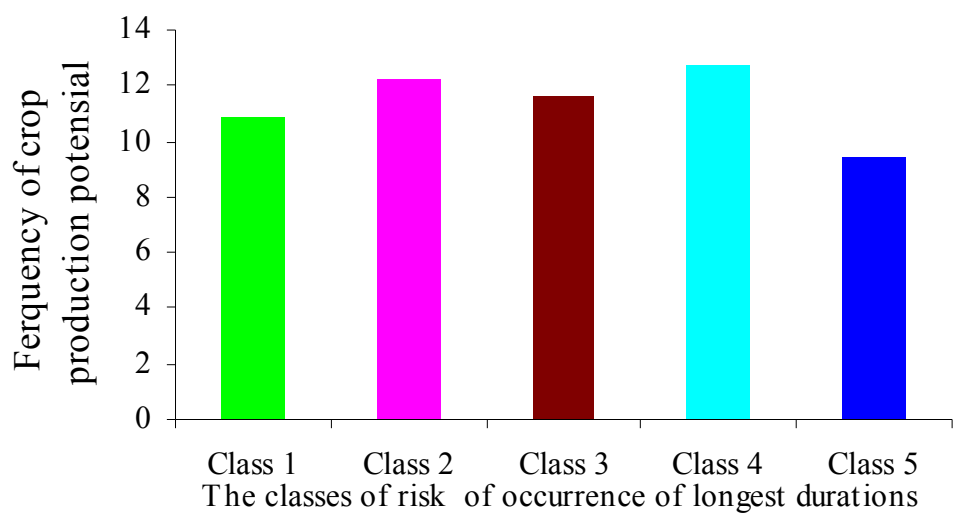

Figure 8 - Overlaid and integrated map of probability of occurrence of longest durations with map of spatial variation of production potential

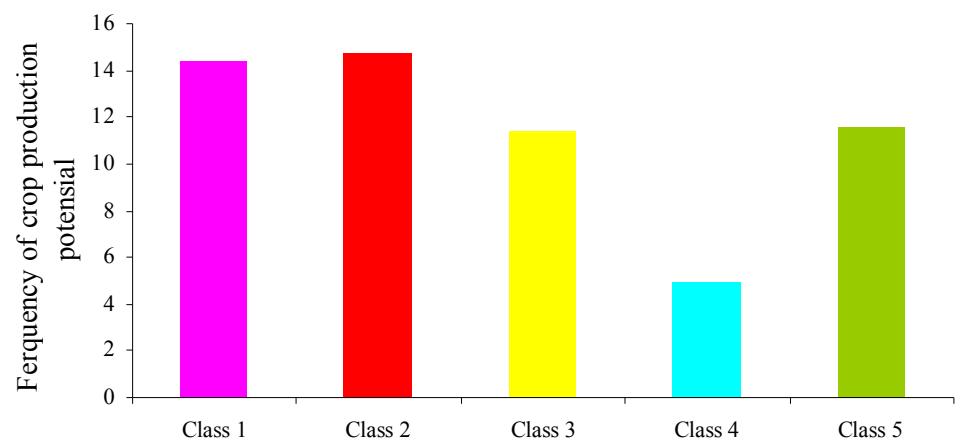

The classes of risk of occurrence ofmost intensity durations

Figure 9 - Overlaid and integrated maps of probability of occurrence of most intensive durations with map of spatial variation of production potential 
Thus, the study of the developed figures through regional analysis functions of GIS can give more insight into the variation trend of spatial suitability of crop production potential in each class of drought occurrence (longest duration and/or most intensive duration). This analysis was performed for the region under study but a sample is presented in Figures 8 and 9.This analysis shows that regions located in class-4 risk of occurrence of the longest drought durations have higher frequency of crop production potential with compare to regions located in class-4 risk of occurrence of most intensive durations.

\section{CONCLUSION}

With experience of consecutive droughts and depletion of available water resources, more accurate planning based on capabilities and constraints in all regions are necessary for increasing productivity of water and soil resources. Drought risk management and drought monitoring with preliminary precautionary measures and adaptation can definitely reduce loses. The development and integration of the results of Agro-ecological Zoning model with the maps of drought risk in a region can help in suitable planning for optimal operation of water and soil resources as well as for looses reduction.

\section{REFERENCES}

[1] Alley, W.M. The Palmer Drought Severity Index: Limitations and assumptions. Journal of Climate and Applied Meteorology. 1984, 23:1100-1109.

[2] Byun, H. R., and Wilhite, D. A. Objective quantification of drought severity and duration. J. of Climate.1999,12: 2747-2756.

[3] Cline, W. Global Warming and Agriculture: Impact Estimates by Country. Washington, DC: Center for Global Development and Peterson Institute for International Economics. 2007.

[4] Darwin, R., M. Tsigas, J. Lewabdrowski, and A. Raneses. World Agriculture and Climate Change. Agricultural Economic Report.1995. no. 703 (June). Washington, DC: US Department of Agricultural, Economic Research Service.

[5] Deng X Z, Huang J K, Rozelle $S$ et al.. Cultivated land conversion and potential agricultural productivity in China. 2006. Land Use Policy, 26(3): 372-384.

[6] FAO (Food and Agriculture Organization of the United Nations). Agro-ecological Zoning Guidelines. Rome: FAO Soils Bulletin. 1996.

[7] Fischer G, Sun L. Model based analysis of future land-use development in China. Agriculture, Ecosystems and Environment. 2001.85(1-3): 163-176.

[8] Fischer, G., M. Shah, F. N. Tubiello, and H. van Velthuizen. Socio-economic and Climate Change Impacts on Agriculture: an Integrated Assessment, 1990-2080. Philosophical Transactions of the Royal Society B. 2005. 360: 2067-2083.

[9] Flug, M., and Campbell, S.G. Drought Allocations Using the Systems Impact Assessment Model: Klamath River. ASCE J. of WRPM. 2005. 131(2):110-115.

[10] Karl, T.R.; and R.W. Knight. Atlas of Monthly Palmer Hydrological Drought Indices (1931-1983) for the Contiguous United States. Historical Climatology Series 3-7, National Climatic Data Center, Asheville, North Carolina. 1985.

[11] Karamouz, M., Torabi, S., and Araghinejad, S. Analysis of Hydrologic and Agricultural Droughts in Central Part of Iran. ASCE, J. of Hydrologic Eng. 2004. 9(5): 402-414.

[12] Lugue, L. Zonificación agroecológica del fresno (Fraxinus pennsylvanica Marshall) y roble(Quercus robur L.) en el Valle de Calamuchita, Córdoba, Argentina (Agroecological zoning of ash (Fraxinus pennsylvanica Marshall) and oak (Quercus robur L.) in the Calamuchita valley, Córdoba, Argentina). Master thesis, Graduate School, Fac. de C. Agrop. Universidad Nac. Cordoba. 2009.185 p.

[13] McKee, T.B.; N.J. Doesken; and J. Kleist. Drought monitoring with multiple time scales. Preprints, 9th Conference on Applied Climatology. 1993.pp. 233-236. January 15-20, Dallas, Texas. 
[14] Palmer, W.C. Meteorological drought. Research Paper No. 45, U.S. Department of Commerce Weather Bureau, Washington, D.C. 1965.

[15] Pratap, T., Pradhan, P., Lotta, P.K., Mya, S., Karim and Nakarmi, G. Geographic Information Systems and Technology application in Agro-ecological zonation of mountain agriculture. Eds. N.S. Jodha, M. Banskota and Tej Pratap, Oxford \& IBH Publishing Co. Pvt. Ltd., New Delhi. 1992.

[16] Ravelo A.C., Abril E.G. 2009. Remote sensing Section IV.8, 9 pages. K. Stigter (Ed.). In press.

[17] Segal, J.L., Mandal, D.K., Mandal, C. and Vadivelu, S. Agro-ecological Region of India. NBSS \& LUP (ICAR) Publication. 1992. 24, Nagpur.

[18] Sen, Z. Probabilistic formulation of spatio-temporal drought pattern. Theoretical Applied Climatology. 1998.61: 197-206.

[19] Shin, H.S., and Salas, J.D. Regional Drought Analysis Based on Neural Networks. ASCE J. of Hydrologic Eng. 2000. 5(2): 145-155.

[20] Subramanian, A.R. Agro-ecological Zones of India. Arch. Met. Geoph. Biocl. 1983. Ser. B32; 329-333.

[21] Venkateshwaralu, J., Ramakrishna, Y.S. and Rao, A.S. Agro-climatic zones of India. Annals of Arid Zone. 1996.35 (1); 1-8. 